\title{
PROPOSAL FOR A HIGHER EDUCATION ADMISSION MANAGEMENT SYSTEM WITH THE USE OF OPEN SOURCE TECHNOLOGIES
}

\author{
Bráulio Alturas ${ }^{1}$ and Junior Marimbique ${ }^{2}$ \\ ${ }^{1}$ Instituto Universitário de Lisboa (ISCTE-IUL), ISTAR-Iscte. Lisboa, Portugal \\ ${ }^{2}$ Instituto Universitário de Lisboa (ISCTE-IUL). Lisboa, Portugal
}

\begin{abstract}
Higher education institutions are characterized by the growth of the student population, the need to align their programs with market demand, and the adoption of new management and service delivery techniques, making it essential to use information technologies. This research project aims to design an information system prototype for a higher education admission management information system and propose open source software engineering tools that can assist its development. This paper presents the main concepts related to information systems, higher education and open source software. The prototype was designed following the object-oriented software development methodology and the software engineering tools were based on the comparison of two tools to three information system software elements namely forms, reports and web portal.
\end{abstract}

\section{KEYWORDS}

Information Systems, Information Technologies, Higher Education, Open Source Software

\section{INTRODUCTION}

In the last decades, there have been several changes in the form of management of organizations, motivated by internal and external changes, including the growth of the organization, globalization and the emergence of new technologies. These transformations, in turn, can change the operating rules, the structure or the organizational objectives (Alturas, 2013)

Higher education institutions (HEIs) have sought to align process management in accordance with the newest premises of business management and service provision. This fact challenges HEIs to align their work processes according to the most modern corporate governance techniques, where information systems and technologies occupy a prominent place 
IADIS International Journal on WWW/Internet

(Machado, 2008). The use of Information Systems (SI), in a higher education institution, helps to save time, increases productivity, allows to perform more tasks than otherwise, and work processes are less bureaucratic (Chimuco and Alturas, 2018).

Although there are many studies on the application of information technologies in higher education institutions, most focus on aspects such as teaching (Lam et al., 2019b; Pedro et al., 2013) or assessment (Alturas and Alturas, 2010; Lam et al., 2019a). This study assumed the existence of several open source software or open source software engineering tools applicable in the development of IS for higher education.

In this article, the design science research methodology is used to create the requirements for the admission system for higher education students in ISPM, a Mozambican HEI, these requirements are used to assess the possibility of applying open source software. The result of this work proves the existence of reusable open source software for the development of higher education IS, with little additional effort.

\section{LITERATURE REVIEW}

\subsection{Information Systems}

Information system can be defined as a set of interrelated components that collect (or retrieve), processes, store, and distribute information to support decision making and control in an organization (Laudon and Laudon, 2019) The common axis found in the research of the information system context is that it is a set of interconnected elements (Ex: people, data, processes, technologies), which aims to produce useful information and knowledge for the organization (Alturas, 2013; Amaral and Varajão, 2007). However, Alturas (2013) and Amaral and Varajão (2007) state that the existence of information systems in an organization does not depend on computers or other computing resources.

A definition of information systems more contextualized to computer science is proposed to us by Carvalho (1996), which he defines as a set of activities and tools that allow organizational agents to inform themselves and obtain the knowledge they need to make decisions (Carvalho, 1996). In this context, the organizational agents, equivalent to people in the definition proposed by Alturas (2013) and Amaral and Varajão (2007), extend to other systems and devices, such as those used in the internet of things and artificial intelligence.

Although the information system concepts proposed above do not directly refer to information technology, in reality it is increasingly rare (...) information systems without computer resources (Alturas, 2013). This thought is also defended by Alter (1999) who adds computers and organizational work processes to the concept of information systems (Alter, 1999).

\subsection{Higher Education Information Systems}

The search for efficiency in the management of the HEI, made them align their management processes in accordance with the newest premises of business management and service provision, where information systems and technologies occupy a prominent place (Machado, 2008). Information technology providers initially responded to the widespread use of IT in 
higher education, providing products adapted for companies, due to the similarity of the administrative structure of universities to large companies (Rabaa'i et al., 2009).

However, according to Rabaa'i et al., (2009) HEIs have their unique nature, which differs from companies. Another not less important aspect of the difference between companies and IES lies in the nature and orientation of these two organizations. While companies are focused on profits, HEIs are mostly supported by public funds and assume the vocation to teach and research, without neglecting the need for sustainability (Noaman and Ahmed, 2015).

The differences between companies and HEIs extend to administrative functions, and therefore to transaction processing systems. For example, while traditional ERP provides basic management functions such as accounting, finance, sales marketing and human resources, ERPs for HEIs require additional functions, which include teaching administration, pedagogical administration, facility management, library management and other functions that are not present in traditional ERP. According to Noaman and Ahmed (2015), the successful implementation of IT in HEIs is conditioned, first of all, by the clear definition of the necessary management functions. Table 1 show the 30 transactional functionalities that HEIs must have.

Table 1. Transactional Functionalities that HEIs must have (adapted from Noaman and Ahmed, 2015)

\begin{tabular}{ll}
\hline FUNCTIONALITY & FUNCTIONALITY \\
\hline 01 Institution profile & 16 Internal massaging \\
02 Staff profile & 17 Alumni management \\
03 Student profile & 18 Hostel management \\
04 Feedback mechanism module & 19 Transportation management \\
05 curriculum & 20 Stuff attendance \\
06 Performance analysis & 21 Semesters Calendar \\
07 Attendance & 22 Library management \\
08 Score card & 23 Accounting \\
09 Online examination & 24 Fees management \\
10 Online assignment & 25 Academic advising \\
11 Admission & 26 Ad hock reporting \\
12 Payroll & 27 Asset Management \\
13 Timetable & 28 Job / requirements analysis \\
14 Event management & 29 Labor market demand \\
15 Notice board & 30 Education / labor market observatory \\
& \\
\hline
\end{tabular}

Another system commonly used in HEIs is CRM, which presents an integrated view of students in all areas of the business, so that they receive a high level of service. Student satisfaction with teaching management services is an important factor in evaluating the quality of higher education, this is where CRM can play an important role. According to Seeman and O'Hara (2006) many students see administrative services as a necessary evil. Thus, an IS that improves CRM, focusing on reducing the steps of administrative tasks, can make HEI more competitive (Seeman and O'Hara, 2006).

The advancement of technologies and the popularization of the Internet within the world population, has allowed the widespread use of e-learning in HEIs, being equivalent to the system for e-business in companies. E-learning systems (also known as LMS - Learning Management Systems) provide a set of features, which allow part of the face contact, necessary between student-teacher and student-student is likely to be dismissed (Pedro et al., 2013). E-learning systems encompass the set of technologies and methodologies to design, make available, 
manage, select and extend education services to people far from the IES physical space. The ideal concept of e-learning, is not limited to transposing content taught in person on the platform, e-learning should involve all other services provided to students normally on campus, which includes, the loan of books, access to the e-book, teaching management services, treasury, student support, among others.

\subsection{Open Source Software}

\subsubsection{Open Source Technologies}

In recent years, there are more and more cases of success in the open source software industry, motivating software engineers and businessmen to adopt open source software in their projects. Open source software is software that can be freely distributed, its code made available free of charge and allowed to change and redistribute the software under certain license terms (Liaskos et al., 2012).

The commonly accepted benefits of open source software are grouped into five categories: social and psychological benefits, benefits of software development methodology, security and risk management benefits, benefits of lifelong software adoption and financial benefits (Williams Van Rooij, 2007).

Simply obtaining open source software does not mean you can do what you want with it. The open source license is the document through which rights holders authorize the use of their works and the respective restrictions. Each open source software can have its specific license; however, the common practice is to reuse the licenses already consolidated within the community. Another factor to be taken into account in the open source software license is the compatibility between licenses, since some technological solutions use the code combination of two or more software, which may have different licenses. The recommendation in this case is to analyze the potential license conflicts before starting a software reuse project.

\subsubsection{Open Source Technologies in Higher Education Institutions}

The operationalization of HEIs can be rationalized by reducing costs with information technologies. The use of open source applications for content management and academic management has been one of the ways to rationalize resources in HEIs (Williams Van Rooij, 2007), since with open source software, developers can customize the system to meet the needs HEIs, reducing the costs of commercial licenses, especially those of periodic payment.

The offer of open source technologies currently occupies a prominent place in higher education, as they offer a set of requirements that fully respond to the needs of most organizations that seek to redefine their work processes based on information technologies (Ávila et al., 2012).

According to Williams van Rooij (2009), the offer of open source technologies for education is not limited only to the content management system or virtual learning environments. These can include internet browsers, data transfer (encryption) software, network management software, routing software, operating systems, application servers and even financial management systems.

The main factors that contribute to the adoption of open source software in higher education are the need to rationalize funds, the increase in the price of licenses to use commercial software and the need for HEIs to acquire more and more software licenses (Williams van Rooij, 2009). 
These three factors emphasize the influence of financial benefits on the adoption of open source technologies in the higher education sector.

\section{METHODOLOGY}

In this work the methodology of design science research (DSR) was used, since the intention is to build an artifact. DSR is the research methodology for building any artifact as an embedded solution to a known and understood research problem (Peffers et al., 2007), it involves a rigorous process for designing artifacts, solving observed problems, making research contributions, evaluate models and publish the results (Hevner et al., 2004). In order to achieve the proposed objectives, the work included the analysis of users, requirements analysis and evaluation of open source software applicable for the management of the student access process to higher education.

The assessment of stakeholders and their needs was carried out through an interview, in which the characteristics of different classes of users are expected to be found, as well as their objectives. The interview was directed to people more involved in the administration of access to HEI and to students and / or student candidates in order to meet their needs.

The evaluation of open source software compares the system requirements to the functions or properties of the software. For this effect, six open source software were selected, those that in the literature review, were identified as being the most used today: two for producing reports, two for managing forms and two for the development of Web portals. Software's comparison focused on features, versatility, dynamics of the development community and business model.

\section{SYSTEM ANALYSIS AND DESIGN}

The analysis of the system's stakeholders makes it possible to identify the characteristics of the people who use the system and its objectives. The interview with students, candidates and members of the ISPM entrance exams committee, the processes, the relationship between processes and stakeholders, as well as their objectives. Table 2 shows the people interviewed.

Table 2. People interviewed

\begin{tabular}{lll}
\hline ORDER & PEOPLE & NUMBER OF PEOPLE \\
\hline 01 & Candidates & 5 \\
02 & Students & 5 \\
03 & Committee members & 10 \\
\hline
\end{tabular}

The interview with the members of the ISPM entrance exams committee allowed us to verify that the main classes of stakeholders in the system are candidates, HEIs and government institutions that manage higher education. The analysis of the objectives focused on the candidates and the HEIs, since these are direct players in the system, as shown in Table 3. 
IADIS International Journal on WWW/Internet

Table 3. Objectives of direct-action stakeholders and IS elements of action

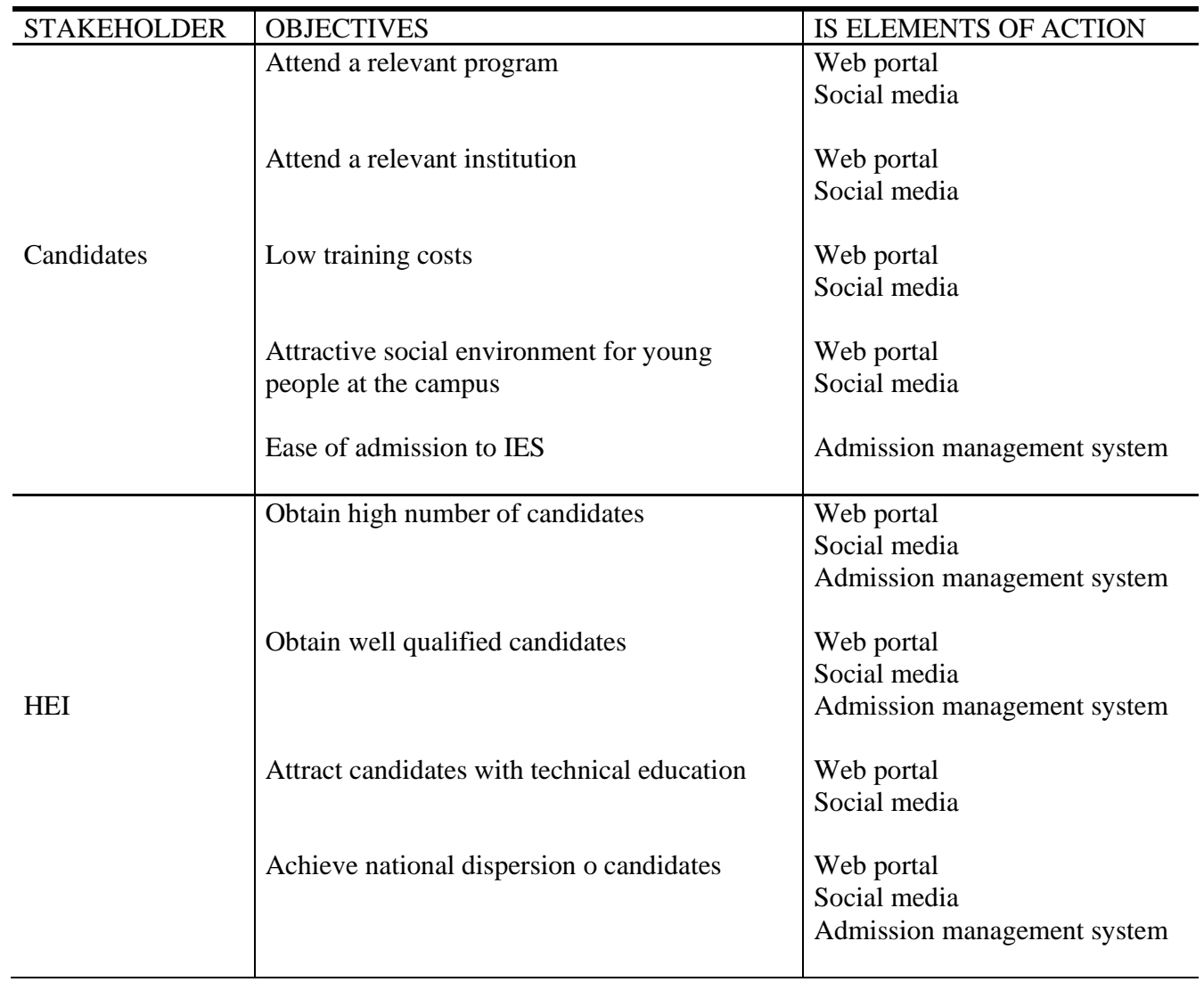

Registration is the first step to start the application process. It establishes the platform's authentication mechanisms and communication mechanisms between users. Email and cell phone are the most used forms for electronic communication in Mozambique, so it is proposed that the system uses email authentication or cell phone authentication.

When submitting the application, the applicant's personal data and the required documentation must be submitted, which can be subdivided into mandatory and optional.

The analysis of the application consists of verifying the compliance of the application, the data and documentation is evaluated with the required requirements. After this process, the application status is announced and can be accepted or not accepted.

The application can be evaluated by examining documents or exams. Upon admission by documentary evaluation, the documentation to be classified is assigned a score and the weighted average of the score of the classifiable documents serves as the final classification of the candidates. In the assessment by exam, candidates are submitted to one or more exams and, as in the documentary assessment, the final classification is the weighted average of the exam scores. 


\section{OPEN SOURCE SOFTWARE EVALUATION}

\subsection{Forms Manager}

\subsubsection{Definition}

Evaluating consists of comparing a given reality to an ideal model, called a standard. In this process, two tools were compared to the system requirements. The necessary components for the electronic admission management system are essentially a form manager, report production tool and web portal. The software evaluation focuses on the potential of these tools in the development of the system.

A form is a web page that has boxes you can type into (Jarrett and Gaffney, 2009). Forms are an essential element for communicating with users of the system, and one of the essential elements for entering data into any information system. The form manager, in this context, has the responsibility to create, format, change and remove data entry fields according to the information to be received.

\subsubsection{WebForm}

WebForm is a forms management tool in the Drupal content management system (SGC) WebForm allows the creation, submission, review, obtaining data and sending notifications. WebForm is used on 480,000 sites and is under the same license as Drupal, GNU General Public License. Version 5.x of the webform has been completely reimplemented as a source code for Drupal 8, improving its integration.

\subsubsection{Orbeon Forms Community Edition (CE)}

Orbeon Forms CE is a forms management tool, which allows the creation and publication of web forms that includes an XForms engine, the form builder and the form editor. This tool has the closed source version and the Community open source version, with the code made available on github under the GNU Lesser General Public License. It is developed in Java by Orbeon, Inc.

\subsubsection{Benchmark}

The two reporting management tools were installed in order to compare their functionalities and verify their alignment with the requirements for the higher education access management system. It was found to be easier to install and configure Drupal + Webform compared to Orbeon Forms CE, however, Orbeon Form has a more pleasant interface.

Table 4 shows the data entry mechanisms. The fact that the webform does not support the answer input field (Yes / No) is disregarded because it is possible to achieve the same effects in the selection field. 
IADIS International Journal on WWW/Internet

Table 4. Data entry mechanism comparison

\begin{tabular}{lcc}
\hline DATA FIELDS & WEBFORM & ORBEON FORMS \\
\hline Text field & Yes & Yes \\
Message field & Yes & Yes \\
E-mail & Yes & Yes \\
Mobile Phone & Yes & Yes \\
Password & Yes & Yes \\
Selection field & Yes & Yes \\
Response field (Yes / No) & Yes & No \\
Checkbox & Yes & Yes \\
Upload files & Yes & Yes \\
Upload photos & Yes & Yes \\
& & \\
Total & $10 / 10$ & $9 / 10$ \\
\hline
\end{tabular}

Both tools have input data validation mechanisms, with the exception of file validation, which requires the addition of code for this purpose, as shown in Table 5.

Table 5. Data validation comparison

\begin{tabular}{lcc}
\hline VALIDATION & WEBFORM & ORBEON FORMS \\
\hline Minimum size & Yes & Yes \\
Maximum size & Yes & Yes \\
Data type & Yes & Yes \\
Mandatory & Yes & Yes \\
Field description & Yes & Yes \\
Custom validation error message & Yes & Yes \\
File validation & No & No \\
Security validation & Yes & No \\
& & \\
Total & $7 / 8$ & $6 / 8$ \\
\hline
\end{tabular}

With regard to the forms and submission management mechanisms, the convenience in both tools is recorded, both provide the same management mechanisms, as shown in Table 6.

Table 6. Forms management mechanisms comparison

\begin{tabular}{lcc}
\hline MANAGEMENT & WEBFORM & ORBEON FORMS \\
\hline Edition & Yes & Yes \\
Save as draft & Yes & Yes \\
Configurable submission period & Yes & Yes \\
Reports & Yes & Yes \\
Messaging & Yes & Yes \\
Total & & \\
\hline
\end{tabular}

Both Webform and Orbeon provide official documentation that includes instructions for installing, building, publishing and managing forms. Webform, in addition to the official documentation, also has documentation from the developer community that addresses the structure of the software and the API, issues that are minimally covered in the Orbeon documentation. 


\subsection{Reporting Tools}

\subsubsection{Definition}

Visualization and reporting tools produce outputs that are designed for the information consumer. These tools generate reports and dashboards with different degrees of detail and sometimes drilldown capabilities (Azvine et al., 2006).

\subsubsection{BIRT}

BIRT, an acronym for Business Intelligence and Reporting Tools, is an open source tool for data visualization and report creation. BIRT is a component of the Eclipse Integrated Development Environment (IDE) that creates a perspective for developing reports and graphs. BIRT is available under the Eclipse Public License.

BIRT has resources for creating reports, complex graphs supporting a wide range of data sources, including the POJO data source, NoSQL, JDBC, Scripted database. With regard to report formats it is possible to extract in PDF, Spreadsheet and XLS.

\subsubsection{JasperSoft Studio}

JasperSoft Studio allows the creation of templates, complex expressions and several report components that include tables, cross-reference tables, lists and graphs. With regard to data sources, it supports big data, JDBC, NoSQL, CSV, JSON, XML, JavaBeans or custom data sources. The reports developed by JasperSoft studio can be published using the JasperSoft server, a tool also available with the open source edition. For this purpose, there is a technical connection mechanism between the two tools, which makes it possible to publish reports. Both JasperSoft Studio and JasperSoft server are available under the Affero General Public License and are maintained primarily by TIBCO Software Inc.

\subsubsection{Benchmark}

The two reporting tools were installed in order to compare their features and check their alignment with the requirements for the access management system to higher education.

There was a trend of application convenience in both tools. The differences are essentially concentrated on the business model.

Both BIRT and JasperSoft studio support SQL, NoSQL, XML, CSV and java objects as data sources, as shown in Table 7. This wide range of supported data sources is partly justified by the fact that the two tools use JDBC, a Java feature for connecting to data sources. The notable difference is in the types of Java objects obtained supported as a data source, with BIRT supporting Plain Old Java Objects (POJO) while JasperSoft Studio favors JavaBeans. 
IADIS International Journal on WWW/Internet

Table 7. Data sources supported by BIRT and JasperSoft Studio

\begin{tabular}{lcc}
\hline DATA SOURCE & BIRT & JASPERSOFT \\
\hline Cassandra Scripted Data & Yes & No \\
CSV data source & Yes & Yes \\
JDBC Connection & Yes & Yes \\
POJO data source & Yes & No \\
Scripted data source & Yes & No \\
XML data source & Yes & Yes \\
JavaBeans & No & No \\
Table Model & No & Yes \\
Map-Based & No & Yes \\
Web service & Yes & Yes \\
& & \\
Total & $7 / 10$ & $7 / 10$ \\
\hline
\end{tabular}

With regard to reporting items, it appears that both tools have the same reporting items, as shown in Table 8, with only a difference in the types of charts available, but according to with the requirements of the admission system to higher education, both tools are considered compatible with respect to the items of report design and templates.

Table 8. Report items comparison

\begin{tabular}{lcc}
\hline REPORT ITEMS & BIRT & JASPERSOFT \\
\hline Label & Yes & Yes \\
Text & Yes & Yes \\
Dynamic Text & Yes & Yes \\
Data & Yes & Yes \\
Image & Yes & Yes \\
Grid & Yes & Yes \\
List & Yes & Yes \\
Table & Yes & Yes \\
Chart & Yes & Yes \\
Cross Tab & Yes & Yes \\
& & \\
Total & $10 / 10$ & $10 / 10$ \\
\hline
\end{tabular}

The traditional mechanism for presenting reports is in the form of a web page, being exportable to other formats. BIRT can be obtained or exported to more document formats compared to JasperSoft Studio, as shown in Table 9. However, other report document formats can be generated or exported from both tools, requiring further development for this purpose. 
Table 9. Report format comparison

\begin{tabular}{lcc}
\hline REPORT FORMAT & BIRT & JASPERSOFT \\
\hline Web & Yes & Yes \\
Spreadsheet & Yes & Yes \\
CSV & Yes & Yes \\
Document & Yes & Yes \\
PostScript & Yes & Yes \\
XML & Yes & No \\
TSV & Yes & No \\
PDF & Yes & Yes \\
XLS & Yes & Yes \\
& & \\
Total & $9 / 9$ & $7 / 9$ \\
\hline
\end{tabular}

Both BIRT and JasperSoft Studio do not have a graphical interface for generating queries, both have simplified mechanisms for creating SQL queries. Table 10 presents the query production resources available in the two tools, where convenience is verified.

Table 10. Query tools comparison

\begin{tabular}{lcc}
\hline QUERY TOOL & BIRT & JASPERSOFT \\
\hline Params & Yes & Yes \\
GUI Query Designer & Yes & Yes \\
Query Editor & Yes & Yes \\
SQL Query log & Yes & Yes \\
Template creator & Yes & Yes \\
Total & & \\
\hline
\end{tabular}

According to Table 15, which seeks to measure the dynamics of the open source community in the tools under analysis, BIRT has the most dynamic development community, since it has the participation of three top technology companies, in addition to greater community intervention in the product development and management process.

\subsection{Web Portal}

\subsubsection{Definition}

Web Portal is a system designed to provide information from different sources. Internet portals often act as gatekeepers to the Internet. Users may begin their sessions on the Internet by visiting a portal, and obtain information like news, weather or stock quotes (Telang and Mukhopadhyay, 2005).

With the possibility of the higher education admission system being made up of different tools, coupled with the fact that it is necessary to make other IES information available to stakeholders, the web portal assumes a predominant role.

Many organizations have adopted the content management system (SGC) as a web portal management tool, quickly aggregating all the information needed to communicate with the public (Rainville-Pitt and D'Amour, 2009). SGC is software for creating websites quickly and easily, where people without programming knowledge can create, publish and update content. 
IADIS International Journal on WWW/Internet

On the other hand, the SGC offers the designer and developers more flexibility in customizing the appearance and functionality of the website (Ghorecha and Bhatt, 2013). Content management systems (SGC), despite seeming to be easy to introduce Web content without the need for knowledge of programming languages, also offer powerful frameworks that facilitate communication with other systems, thus constituting an important tool for the development of Web portals. In this work we analyzed two popular open source SGCs, Joomla and Drupal.

\subsubsection{Joomla}

Joomla is a SGC that focuses on the ease of creating, editing, publishing and archiving web content. The ability to process data from other data sources is thanks to its framework, which has simplified mechanisms for adding add-ons that extend the power of this SGC, for this reason Joomla can be considered both as a product for the end user, as well as a software engineering tool. Its use ranges from simple blogs to powerful portals.

\subsubsection{Drupal}

Drupal seeks to distance itself from other GSCs, by focusing on security, development standards and framework, these factors justify its use as a portal for large companies and in situations where multiple data sources exist. The Drupal framework, often cited as powerful and scalable, has the ability to integrate with other services and applications, which is also the main marketing element of the tool. Unlike Joomla, Drupal is considered more as a software engineering tool than an SGC.

\subsubsection{Benchmark}

The most famous content management systems developed in PHP have a trend towards functional convenience, which is also confirmed in Table 11, this makes comparisons between these tools to focus on non-functional aspects such as scalability, speed, versatility, API and dynamics of the development community.

Table 11. Functionalities comparison

\begin{tabular}{lcc}
\hline FUNCTIONALITY & DRUPAL & JOOMLA \\
\hline Mobile device support & Yes & Yes \\
Responsive design & Yes & Yes \\
Multiple language support & Yes & Yes \\
Integration with social network & Yes & Yes \\
File Manager & Yes & Yes \\
Identity and access managemer & Yes & Yes \\
SEO & Yes & Yes \\
Collaboration Forum & Yes & Yes \\
Asynchronous communication & Yes & Yes \\
Synchronous communication & Yes & Yes \\
& & \\
Total & $10 / 10$ & $10 / 10$ \\
\hline
\end{tabular}

According to Tables 12 and 13, Drupal supports more database systems and Web servers, both of which do not support non-relational databases. The fact that Joomla does not support popular DBMSs such as MariaDB and SQL Lite puts you at a competitive disadvantage in this regard. 
PROPOSAL FOR A HIGHER EDUCATION ADMISSION MANAGEMENT SYSTEM WITH THE USE OF OPEN SOURCE TECHNOLOGIES

Table 12. Database support comparison

\begin{tabular}{lcc}
\hline DATABASE & DRUPAL & JOOMLA \\
\hline MySQL & Yes & Yes \\
Maria DB & Yes & No \\
SQL Lite & Yes & No \\
Mongo DB & No & No \\
PostgreSQL & Yes & Yes \\
MS SQL Server & Yes & Yes \\
Total & & \\
\hline
\end{tabular}

The fact that Joomla does not support Hiawatha, as shown in Table 13, may not have much impact due to the low market share of this Web server, but this makes Drupal more versatile than Joomla.

Table 13. Web server comparison

\begin{tabular}{lcc}
\hline DATABASE & DRUPAL & JOOMLA \\
\hline Apache & Yes & Yes \\
MS IIS & Yes & Yes \\
Nginx & Yes & Yes \\
Hiawatha & Yes & No \\
& & \\
Total & $4 / 4$ & $3 / 4$ \\
\hline
\end{tabular}

As shown in Table 14, Drupal and Joomla support the same Data API.

Table 14. Data API comparison

\begin{tabular}{lcc}
\hline DATA API & DRUPAL & JOOMLA \\
\hline SOAP Web services & Yes & Yes \\
SOAP Client & Yes & Yes \\
REST Web service & Yes & Yes \\
REST Client & Yes & Yes \\
CRUD & Yes & Yes \\
Storage API & Yes & Yes \\
Total & & \\
\hline
\end{tabular}

Although the data in Table 15 suggests the same level of dynamics in the development community, it should be noted that Drupal has a developer community made up of more developers than Joomla and provides better documentation support. 
IADIS International Journal on WWW/Internet

Table 15. Dynamics of the development community

\begin{tabular}{|c|c|c|c|c|c|c|}
\hline & \multicolumn{2}{|c|}{ FORMS MANAGER } & \multicolumn{2}{|c|}{ REPORTING TOOLS } & \multicolumn{2}{|c|}{ WEB PORTAL } \\
\hline & WEBFORM & ORBEON & BIRT & JASPERSOFT & JOOMLA & DRUPAL \\
\hline Discussion forum & 3 & 1 & 3 & 2 & 3 & 3 \\
\hline Forum of doubts & 3 & 1 & 3 & 3 & 3 & 3 \\
\hline FAQ & 3 & 2 & 3 & 1 & 3 & 3 \\
\hline Dedicated Help Desk & 3 & 3 & 3 & 2 & 3 & 3 \\
\hline Incident management & 3 & 1 & 3 & 1 & 3 & 3 \\
\hline Other entities participating & 3 & 0 & 3 & 0 & 3 & 3 \\
\hline in the development & 3 & 2 & 3 & 2 & 3 & 3 \\
\hline Developer documentation & 3 & 3 & 3 & 3 & 3 & 3 \\
\hline Documentation for using & 3 & 3 & 3 & 3 & 3 & 3 \\
\hline the application & 3 & 2 & 3 & 1 & 3 & 3 \\
\hline Development Center & 3 & 1 & 3 & 3 & 3 & 3 \\
\hline $\begin{array}{l}\text { Community bug fix } \\
\text { proposal } \\
\text { Adding new modules / } \\
\text { features by the community } \\
\text { Code improvement }\end{array}$ & 3 & 0 & 3 & 0 & 3 & 3 \\
\hline Total & 36 & 19 & 36 & 21 & 36 & 36 \\
\hline
\end{tabular}

Scores: 1 - Has the service / product; 2 - The community participates; 3 - The community participates in decision making

\section{CONCLUSION}

This article, which started from the principle of the existence of open source technologies for the IES admission management system, for this purpose, was supported by the design science research methodology to obtain the main requirements of the system as well as the design of diagrams and report templates.

During the analysis and design of the system, it was found that most of the candidates' objectives are related to the availability of information related to the courses, IES and place of study. For this purpose, the web portal and social networks constitute the main means of interaction. The intersection of the objectives of the HEI and the candidates with elements of SI action allowed us to identify the elements of entry, reporter and dissemination of data or information that are most critical for the higher education admission system. This made the evaluation of open source software to focus on tools for forms management, reporting tools and content management system.

The software assessment concluded that the more freedom the license grants, the more dynamic the software community is and the more dynamic the community is, the less risk for adoption. This article proposes the adoption of Drupal, Webform, and BIRT as tools for the development of the IS of the case study, and the application in other HEIs needs further analysis.

The objectives of this work were achieved by obtaining the functional requirements and proposing software components for development. However, this work is limited on the one hand, to data collected in a single HEI, on the other hand, it does not address data analysis, an essential component in the production of information for decision making. Further studies are recommended, involving more HEIs, comparing admission processes to HEIs in different countries, comparing public HEI versus private HEI, comparing student requirements with those of employees and the data analysis component for admission to higher education. 


\section{REFERENCES}

Alter, S., 1999. A General, Yet Useful Theory of Information Systems. Communications of the Association for Information Systems, Vol. 1, Article 13, pp. 1-70. https://doi.org/10.17705/1 cais.00113

Alturas, A.P., Alturas, B., 2010. Differentiation in the assessment between different groups of students: are experience and maturity more important than learning time? International Journal of Information and Operations Management Education, Vol. 3, No. 3, pp. 256-271. https://doi.org/10.1504/IJIOME.2010.033549

Alturas, B., 2013. Introdução aos Sistemas de Informação Organizacionais [Introduction to Organizational Information Systems]. Edições Sílabo, Lisboa.

Amaral, L., Varajão, J., 2007. Planeamento de sistemas de informação [Information Systems Planning], 4th ed. FCA - Editora de Informática, Lisboa, Portugal.

Ávila, L., Teixeira, L., Almeida, P., 2012. Desmaterialização de processos com recurso a tecnologias open-source numa instituição de ensino superior [Dematerialization of processes using open-source technologies in a higher education institution], in: Atas da $12^{a}$ CAPSI - Conferência da Associação Portuguesa de Sistemas de Informação. APSI (Associação Portuguesa de Sistemas de Informação), Guimarães, Portugal, pp. 200-211. https://doi.org/http://dx.doi.org/10.18803/capsi.v12.200-211

Azvine, B., Cui, Z., Nauck, D.D., Majeed, B., 2006. Real time business intelligence for the adaptive enterprise, in: CEC/EEE 2006 Joint Conferences. pp. 29-36. https://doi.org/10.1109/CECEEE.2006.73

Carvalho, J.Á., 1996. Desenvolvimento de sistemas de informação: da construção de sistemas informáticos à reengenharia organizacional [Development of information systems: from the construction of computer systems to organizational reengineering]. Universidade do Minho.

Chimuco, Y.G., Alturas, B., 2018. Avaliação do impacto do Hipermanager nos processos de trabalho: Aplicação aos docentes de dois colégios em Moçâmedes , Angola [Evaluation of the impact of Hipermanager on work processes: Application to teachers of two colleges in Moçâmedes, Angola], in: Atas da $18^{a}$ CAPSI - Conferência da Associação Portuguesa de Sistemas de Informação. APSI (Associação Portuguesa de Sistemas de Informação), Santarém, Portugal, pp. 1-15.

Ghorecha, V., Bhatt, C., 2013. A guide for Selecting Content Management System for Web Application Development. International Journal of Advance Research in Computer Science and Management Studies, Vol. 1, No. 3, pp. 13-17.

Hevner, A.R., March, S.T., Park, J., Ram, S., 2004. Design Science In Information Systems Research. Management Information Systems Quarterly, Vol. 28, No. 1, pp. 75-105.

Jarrett, C., Gaffney, G., 2009. Forms That Work: Designing Web Forms for Usability. Morgan Kaufmann, Amsterdam, Netherlands.

Lam, P., Lau, C., Chan, C., 2019a. Strategies to flip a classroom: lessons learnt from a joint-university project. IADIS International Journal on WWW/Internet, Vol. 17, No. 1 , pp. 51-65.

Lam, P., Lau, C.K.M., Wong, K., Chan, C.H., 2019b. Continuous Use of Student Response Systems in University Classes : a Quantitative Study of Student Response Rates. IADIS International Journal on WWW/Internet, Vol. 17, No. 2, pp. 1-13.

Laudon, K.C., Laudon, J.P., 2019. Management Information Systems: Managing the Digital Firm, 16th ed. Pearson Education.

Liaskos, S., Khan, S.M., Litoiu, M., Jungblut, M.D., Rogozhkin, V., Mylopoulos, J., 2012. Behavioral adaptation of information systems through goal models. Information Systems, Vol. 37, No. 8, pp. 767-783. https://doi.org/10.1016/j.is.2012.05.006

Machado, L.E., 2008. Gestão estratégica para instituições de ensino superior privadas [Strategic management for private higher education institutions]. FGV Editora. 
IADIS International Journal on WWW/Internet

Noaman, A.Y., Ahmed, F.F., 2015. ERP Systems Functionalities in Higher Education. Procedia Computer Science, Vol. 65, pp. 385-395. https://doi.org/10.1016/j.procs.2015.09.100

Pedro, I., Alturas, B., Laureano, R.M.S., 2013. A aceitação do Moodle em função do carácter mandatório da sua utilização [Moodle acceptance according to its mandatory use], in: 8th Iberian Conference on Information Systems and Technologies, CISTI 2013.

Peffers, K., Tuunanen, T., Rothenberger, M.A., Chatterjee, S., 2007. A design science research methodology for information systems research. Journal of Management Information Systems, Vol. 24 , No. 3, pp. 45-77. https://doi.org/10.2753/MIS0742-1222240302

Rabaa'i, A.A., Bandara, W., Gable, G.G., 2009. ERP Systems in the Higher Education Sector: A Descriptive Case Study, in: 20th Australian Conference on Information Systems. Association for Information Systems, Melbourne, Australia, pp. 456-470.

Rainville-Pitt, S., D’Amour, J.M., 2009. Using a CMS to create fully accessible web sites. Journal of Access Services, Vol. 6, No. 1-2, pp. 261-264. https://doi.org/10.1080/15367960802305896

Seeman, E.D., O'Hara, M., 2006. Customer relationship management in higher education: Using information systems to improve the student-school relationship. Campus-Wide Information Systems, Vol. 23, No. 1, pp. 24-34. https://doi.org/10.1108/10650740610639714

Telang, R., Mukhopadhyay, T., 2005. Drivers of Web portal use. Electronic Commerce Research and Applications, Vol. 4, No. 1, pp. 49-65. https://doi.org/10.1016/j.elerap.2004.10.004

Williams van Rooij, S., 2009. Adopting open-source software applications in U.S. higher education: A cross-disciplinary review of the literature. Review of Educational Research, Vol. 79, No. 2, pp. 682-701. https://doi.org/10.3102/0034654308325691

Williams Van Rooij, S., 2007. Perceptions of open source versus commercial software: Is higher education still on the fence? Journal of Research on Technology in Education, Vol. 39, No. 4, pp. 433-453. https://doi.org/10.1080/15391523.2007.10782491 